\title{
MOTIVAÇÕES INICIAIS PARA ELABORAÇÃO DE DIRETRIZES DA EDUCAÇÃO ESCOLAR QUILOMBOLA NA BAHIA
}

Suely Noronha de Oliveira (PUC-RIO)*

\section{RESUMO}

Para os quilombolas, a promulgação da Lei $n^{\circ} 10.639 / 2003$, que torna obrigatório o ensino da história e da cultura afro-brasileira e africana nas instituições de ensino foi uma conquista, porém não o suficiente para atender demandas escolares e educativas deste grupo. Essa ausência motivou as organizações quilombolas a inserir a educação escolar quilombola como uma demanda no rol de debates sobre políticas públicas de diversidade em educação no Brasil. Este artigo apresenta uma pesquisa sobre o processo de construção de Diretrizes Curriculares para a Educação Escolar Quilombola no estado da Bahia e sua relação com a política nacional. Privilegia-se aqui uma análise do processo local de construção da demanda no estado, focalizando as motivações iniciais e o contexto organizativo-político. A pesquisa utilizou a metodologia qualitativa, com observação participante, trabalho de campo de caráter etnográfico (Salvador-BA), análises de fontes escritas (documentos oficiais) e orais (conversações informais, participação em audiências públicas e entrevistas semiestruturadas com líderes quilombolas, gestores, consultores e investigadores). Como resultado foi produzida uma narrativa temporal analítica das motivações iniciais para a construção de Diretrizes Curriculares para a Educação Escolar Quilombola no estado da Bahia, identificando as continuidades e descontinuidades no seu desenvolvimento.

Palavras-chave: Educação escolar quilombola. Quilombos. Políticas de diversidade. Políticas educacionais.

\section{ABSTRACT \\ INITIAL MOTIVATIONS FOR THE ELABORATION OF GUIDELINES FOR QUILOMBOLA SCHOOL EDUCATION IN BAHIA}

For the quilombolas, the enactment of Law 10.639/2003, which obliges the teaching of Afro-Brazilian and African history and culture in educational institutions, was considered by them a conquest, but it was not enough to meet school demands and educational concerns of this group. This situation motivated quilombola organizations to introduce quilombola school education as a demand in the debate agenda on public policies of diversity in Brazilian education. This article presents an investigation about the construction process of the Curriculum Guidelines for Quilombola School Education in the state of Bahia and its relationship with national politics. An analysis of the local process of construction of the demand in the state is realized, focusing the initial motivations and the organizational-political context. The research used qualitative

Mestre em Educação pela Pontifícia Universidade Católica do Rio de Janeiro (PUC-Rio). Membro do grupo Ciudadanía, Educación y Diversidad de la Faculdad de Educación de la Pontificia Universidad Católica del Perú (PUC/Perú). E-mail: suelynoronha@gmail.com 
methodology, with participant observation, fieldwork of ethnographic character (Salvador-BA), analysis of written sources (official documents) and oral sources (informal conversations, participation in public hearings and semi-structured interviews with quilombola leaders, consultants and researchers). The result of this investigation is a temporal analytical narrative of the initial motivations for the construction of Curriculum Guidelines for Quilombola School Education in the state of Bahia. This article achieve to identify the continuities and discontinuities in its development.

Keywords: School education quilombola. Quilombos. Diversity policies. Educational policies.

\section{RESUMEN}

\section{MOTIVACIONES INICIALES PARA ELABORACIÓN DE DIRECTRICES DA EDUCACIÓN ESCOLAR QUILOMBOLA EN BAHIA}

Para los quilombolas, la promulgación de la Ley 10.639/2003 que hace obligatorio la enseñanza de historia y de la cultura afro-brasileña y africana en instituciones educativas, fue considerada por ellos una conquista, sin embargo no fue suficiente para atender demandas escolares y educativas de este grupo. Esa situación motivó a las organizaciones quilombolas a introducir la educación escolar quilombola como una demanda en la agenda de debate sobre políticas públicas de diversidad en educación en el Brasil. Este artículo presenta una investigación sobre el proceso de construcción de Directrices Curriculares para la Educación Escolar Quilombola en el estado de Bahia y su relación con la política nacional. Aquí se realiza un análisis del proceso local de construcción de la demanda en el estado, enfocando las motivaciones iniciales y el contexto organizativo-político. La investigación utilizó la metodología cualitativa, con observación participante, trabajo de campo de carácter etnográfico (SalvadorBA), análisis de fuentes escritas (documentos oficiales) y orales (conversaciones informales, participación en audiencias públicas, entrevistas semiestructuradas con quilombolas, gestores, consultores e investigadores). Como resultado fue producida una narrativa temporal analítica de motivaciones iniciales para construcción de Directrices Curriculares para la Educación Escolar Quilombola en Bahia, identificando las continuidades y discontinuidades en su desarrollo.

Palabras clave: Educación escolar quilombola. Quilombos. Políticas de diversidad. Políticas educacionales.

\section{Introdução e contexto}

A temática do estudo é a questão da educação escolar quilombola, ${ }^{1}$ mais precisamente a adoção desta categoria na elaboração de políticas públicas.

É nos anos 2000, por sua vez, que o debate sobre

$1 \mathrm{O}$ conceito de educação escolar quilombola compreende escolas que atendem estudantes oriundos de territórios quilombolas e/ou escolas que se encontram localizadas em território quilombola, “[...] é desenvolvida em unidades educacionais inscritas em suas terras e cultura, requerendo pedagogia própria em respeito à especificidade étnico-cultural de cada comunidade e formação específica de seu quadro docente, observados os princípios constitucionais, a base nacional comum e os princípios que orientam a Educação Básica brasileira". (BRASIL, 2013, p. 42). quilombos ${ }^{2}$ - e com ele, uma série de demandas

2 Não existe um conceito único sobre quilombos, permanece ainda hoje como um conceito em disputa. Para este trabalho tomamos como orientadores os conceitos formulados pela Associação Brasileira de Antropologia (ABA): "Consideram-se remanescentes de quilombo grupos que desenvolveram práticas de resistência na manutenção e reprodução de seus modos de vida característicos num determinado lugar, cuja identidade se define por uma referência histórica comum, construída a partir de vivências e valores partilhados" (ASSOCIAÇÃO BRASILEIRA DE ANTROPOLOGIA, 1994 apud ARRUTI, 2006, p. 92). E o conceito adotado pelo Decreto $\mathrm{n}^{\circ}$ $4.887 / 2003$, que regulamenta o procedimento para identificação, reconhecimento, delimitação, demarcação e titulação das terras ocupadas por remanescentes das comunidades dos quilombos: 
por direitos sociais, dentre eles o direito por uma educação escolar específica - ganha espaço na cena pública, político-governamental e acadêmica. $\mathrm{Ou}$ seja, a educação escolar quilombola tornou-se pauta de políticas governamentais e passou a configurar, junto à educação indígena e à educação do campo, o cenário de reconhecimento e disputa por políticas de diversidade na educação.

As políticas de diversidade conquistaram visibilidade dentro do espaço político-governamental e, com base nesses princípios, foram sancionadas algumas leis, dentre elas a Lei $n^{0} 10.639 / 2003$ (BRASIL, 2003a), que torna obrigatório o ensino da história e da cultura afro-brasileira e africana em todas as escolas do país. Estas iniciativas, junto a outras ações e circunstâncias, possibilitaram a ampliação do debate público sobre educação em comunidades quilombolas.

A aprovação das Diretrizes Curriculares Nacionais para a Educação Escolar Quilombola (BRASIL, 2012) foi realizada em junho de 2012 pela Câmara de Educação Básica do Conselho Nacional de Educação e homologada pelo ministro da Educação em novembro do mesmo ano. No texto das diretrizes encontra-se a organização necessária para implementação da política pelos respectivos entes da federação (governo federal, estados e municípios): concepção, princípios, objetivos, etapas e modalidades, projeto político pedagógico, currículo, gestão, avaliação, formação de professores, dentre outros.

Essas Diretrizes foram construídas a partir de consultas públicas oficiais nos estados do Maranhão, da Bahia e em Brasília, realizadas pelo Conselho Nacional de Educação (CNE)/Ministério da Educação (MEC), assim como de consultas públicas em outros estados e municípios, a partir de iniciativas locais. As consultas públicas realizadas nos estados, reivindicadas pelas organizações quilombolas e instituições parceiras, tiveram a missão de estruturar uma proposta de política educacional com a diversidade local característica das comunidades quilombolas existentes no país (embora as audiências tenham obtido uma participação considerável de lideranças quilombolas de diferentes

"considera-se os grupos étnico-raciais definidos por autoatribuição, com trajetória histórica própria, dotados de relações territoriais específicas, com presunção de ancestralidade negra relacionada com a resistência à opressão histórica" (BRASIL, 2003b). estados, estas não supriram a demanda diante da diversidade encontrada).

É importante destacar que, antes da implementação de políticas governamentais e de legislação específica, já havia algumas ações em comunidades quilombolas direcionadas a uma educação escolar diferenciada, a exemplo do Projeto Vida de Negro (1988 a 2003) do Centro de Cultura Negra no Maranhão, ${ }^{3}$ da Escola Maria Felipa (2001) do quilombo Mangal/Barro Vermelho na Bahia, ${ }^{4}$ do processo de construção do Projeto Político Pedagógico da escola do quilombo Conceição das Crioulas, em Pernambuco (2002), ${ }^{5}$ a proposta de escola quilombola sistematizada no Projeto Vivência de Saberes, do quilombo Campinho da Independência, Rio de Janeiro (2005). ${ }^{6}$ Esta, segundo assessores da ONG que apoiou o processo, afirmou que a comunidade discute a função social da escola desde os anos de 1990, junto ao processo de reivindicação pelo território quilombola. Tanto na Bahia quanto em Pernambuco, as lideranças quilombolas enxergaram a escola da comunidade como parceira necessária ao projeto coletivo da comunidade. Estas desenvolveram, em parcerias com universidades e ONGs, metodologias de formação de professores quilombolas, assim como identificaram elementos para se pensar uma educação escolar diferenciada.

Anterior à discussão e proposição nacional das diretrizes curriculares para Educação Escolar Quilombola, aprovadas em 2012 pelo Conselho Nacional de Educação, havia estados brasileiros discutindo políticas públicas específicas para esta modalidade de educação, a exemplo da Secretaria Estadual de Educação do Estado da Bahia, através da Coordenação de Educação para as Relações Étnico-Raciais e Diversidade, criada em 2008.

A Bahia foi o terceiro estado a propor o debate sobre a construção de diretrizes curriculares para esta modalidade de educação. O Mato Grosso, em 2007, iniciou tal processo, mas formulou apenas orientações curriculares ${ }^{7}$. O estado do Paraná, através da Secretaria de Estado da Educação, aprovou

3 Ver Almeida (2002) e Sociedade Maranhense de Direitos Humanos, Centro de Cultura Negra do Maranhão e Projeto Vida de Negro (2005).

4 Ver Oliveira (2006).

5 Ver Silva (2012).

6 Ver Arruti, Maroun e Carvalho (2011).

7 Ver Mato Grosso (2010). 
em 2010 uma Proposta Pedagógica para a Educação Escolar Quilombola no estado: Escola Quilombola e Etnodesenvolvimento. ${ }^{8}$ Em nível municipal, temos a experiência de Santarém, no Estado do Pará, que aprovou, em 2009, uma Resolução, ${ }^{9}$ na qual assegura em Lei a obrigatoriedade de o poder público municipal efetivar políticas de educação para as comunidades quilombolas do município.

Ou seja, esses quatro estados foram os primeiros a discutir e criar condições político-pedagógicas legitimando a importância das políticas de diversidade na educação para comunidades quilombolas. Tais iniciativas produziram documentos pedagógicos orientadores, assim como institucionalizaram políticas educacionais que, posteriormente, contribuíram para a elaboração de uma política nacional específica de educação escolar para as comunidades quilombolas.

No caso das experiências quilombolas, o debate sobre a institucionalização de políticas de educação escolar específica antecedeu, em parte, um acúmulo de experiências dessas comunidades no âmbito da escola. $\mathrm{O}$ estudo sobre quilombos enquanto grupo específico dotado de particularidade é recente, o que justifica o pouco acúmulo formal de tais experiências com a escolarização. Um pouco diferente do processo da educação indígena e da educação do campo, que a partir de processos de escolarização já institucionalizados na prática, no âmbito da educação regular, reivindicaram uma política de reconhecimento e validação das experiências existentes, assim como de suas metodologias.

Os procedimentos metodológicos adotados neste trabalho atendem às exigências de uma pesquisa acadêmica, desenvolvida entre os anos de $2011 \mathrm{e}$ 2013, na interface da antropologia com a educação. ${ }^{10} \mathrm{~A}$ pesquisa foi orientada por metodologia

8 Ver Paraná (2010).

9 Resolução nº 07/2009 do Conselho Municipal de Educação de Santarém, Pará, que apresenta diretrizes para o funcionamento das escolas quilombolas e dá outras providências. Ver Melo (2013).

10 Os dados da pesquisa começaram a ser coletados desde o ano de 2010, na condição de participante-pesquisadora de um grupo de pesquisa na Universidade Federal da Bahia (Redepect-UFBA). E em 2011, já na condição de pesquisadora e membro do Laboratório de Antropologia dos Processos de Formação (LAPF/PUC-Rio). Obteve-se considerável material, na forma de observação participante, registros escritos e orais, imagens, anotações e gravação de áudios, que permitiram a compreensão em perspectiva e o acompanhamento da temática da educação escolar quilombola em cenário local (Bahia) qualitativa, com observação participante, trabalho de campo de caráter etnográfico, análises de fontes escritas (documentos oficiais) e orais (conversações informais, participação em audiências públicas organizadas pelo governo e entrevistas semiestruturadas com líderes quilombolas, gestores, consultores e investigadores no campo de estudo).

\section{O processo de construção da política: o estado da Bahia}

A Bahia foi o terceiro estado brasileiro a debater e propor a elaboração de diretrizes curriculares estaduais para a educação escolar quilombola. $\mathrm{O}$ início do debate e da proposição de política intersetorial e educacional para comunidades quilombolas no Estado deram-se, legalmente, através da Secretaria de Promoção da Igualdade Racial (Sepromi), em 2007, e da Coordenação de Educação para as Relações Étnico-Raciais e Diversidade, em 2008. É importante destacar que a Sepromi era responsável por articular diferentes secretariais de Estado e propor políticas para as comunidades quilombolas, através da elaboração participativa dos planos de desenvolvimento.

\section{Motivações iniciais: política para educação escolar quilombola no estado da Bahia}

Analisando relatórios das audiências públicas estaduais realizadas na Bahia, assim como as transcrições das entrevistas realizadas, foi possível concluir que as motivações iniciais para a construção de uma proposta de política estadual de educação para as comunidades quilombolas no estado pareceram menos uma estratégia e intenção originária da Secretaria Estadual de Educação do Estado da Bahia (SEC/BA), assim como da equipe inicialmente constituída para compor uma coordenação específica na SEC para tratar das questões étnico-raciais na educação.

Então eu não entrei nem para trabalhar com educação quilombola, porque eu não sabia nada de quilombos, nunca tinha trabalhado nada, absolutamente nada com quilombos, e eu achava que era uma demanda tão densa que não era ali que deveria ficar. E comecei a trabalhar com o que eu achava que era priorida- 
de, eu achava, não, eu fui encomendada para essa prioridade, que era implementar a Lei ${ }^{\circ} 10.639$. (ENTREVISTADA A, 2012). ${ }^{11}$

No caso específico da Bahia, havia uma demanda das organizações e movimentos negros do estado, em especial dos situados na capital baiana, exigindo da Secretaria Estadual de Educação a participação em eventos e debates sobre a Lei $\mathrm{n}^{\circ}$ $10.639 / 2003$ e, consequentemente, o cumprimento da referida Lei. No ano de 2005, a Prefeitura Municipal de Salvador publicou ações e orientações para implementação da Lei no 10.639/2003 - Educação das Relações Étnico-raciais e para o Ensino da História e Cultura Afro-brasileira e Africana - na Educação Fundamental, tendo o CEAFRO ${ }^{12}$ como órgão consultor. É importante adiantar que este Programa, além de consultor, atuou também como agência que organizou e produziu demandas referentes à aplicação da Lei n ${ }^{\circ} 10.639 / 2003$, tanto no município de Salvador quanto no Estado.

Também em 2005 foi realizado o Fórum Estadual Educação e Diversidade Étnico-Racial, na cidade de Salvador, por iniciativa da Coordenadoria-Geral de Diversidade e Inclusão Educacional da Secretaria de Educação Continuada, Alfabetização e Diversidade (SECAD/MEC). ${ }^{13}$ A partir deste evento foram criados Fóruns nos estados brasileiros para tratar da temática.

De acordo com a carta produzida no evento, este contou com a participação de representantes do Governo do Estado, Secretarias Municipais, Instituições Públicas, Fórum de Quilombos Educacionais da Bahia, Instituições de Ensino Superior, Entidades Sindicais, Lideranças Políticas,

11 Entrevista realizada com a ex-coordenadora de diversidade da Secretaria de Educação do Estado da Bahia, no dia 13 de junho de 2012, em Salvador, Bahia.

12 O CEAFRO é o programa de educação para igualdade racial e de gênero do Centro de Estudos Afro-Orientais (CEAO), Unidade de Extensão da Universidade Federal da Bahia, em desenvolvimento desde 1995. Tem como principal compromisso estabelecer diálogo entre a Universidade Federal da Bahia, a Escola Pública e as Organizações do Movimento Negro da Bahia.

13 A SECAD/MEC sofreu mudanças de gestão e de concepção com o passar do tempo. Uma das primeiras gestoras dessa secretaria foi Eliane Cavalleiro (2004-2006), ativista do movimento negro e pesquisadora doutora da temática do racismo na educação. Em fevereiro de 2012, o nome da secretaria sofre alterações passando a chamar-se Secretaria de Educação Continuada, Alfabetização, Diversidade e Inclusão (SECADI), sob a coordenação da ex-gestora da Secretaria de Educação Especial (SEESP), Cláudia Pereira Dutra.
Representantes de Comunidades Remanescentes de Quilombos, Movimentos Negros, Organizações Não Governamentais e Educadores de regiões do Estado.

Nessa carta, os grupos apresentaram lacunas na implementação da Lei $n^{\circ} 10.639$ e apontaram soluções e proposições, dentre elas: a necessidade de criação e legitimação do Fórum Permanente de Educação e Diversidade Étnico-Racial; a criação de órgão específico nas secretarias de educação estadual e municipal - para tratar da implantação e aplicabilidade da Lei n ${ }^{\circ} 10.639$; e a criação da Secretaria Estadual de Promoção da Igualdade Racial (Sepromi).

As eleições para governador em 2006 culminaram com a vitória do candidato do Partido dos Trabalhadores, o qual sustentava uma proposta de governo popular, ${ }^{14}$ tendo como horizontes a participação e a proximidade com os movimentos sociais e populares. Uma parcela significativa do movimento negro baiano mostrou-se favorável a essa candidatura. Com as eleições de 2006, os governos federal e estadual ficaram mais próximos e as reivindicações dos grupos político-culturais, que apoiaram as eleições, renovaram-se, exigindo a construção e a implementação de políticas.

O cenário político-organizativo era fértil para discussão, proposição e efetivação das políticas de ação afirmativa, étnico-racial e políticas de diversidade em geral. Havia instituições civis com maior tempo de organização social em nível de estado (movimentos/entidades negras) e outras mais jovens e em processo (organizações quilombolas); junto a isso, há a legitimidade do estado da Bahia diante da temática: Salvador é a cidade com a maior população negra no Brasil e o estado possui o maior número de comunidades quilombolas

14 A escolha do secretário estadual de Educação, Adeum Hilário Sauer (2006-2009), também estava vinculada ao perfil do atual governo. Professor da Universidade Estadual de Santa Cruz (UESC), formado em Filosofia e Direito, com mestrado em Ciência Política; de 2001 a 2005 foi presidente da União Nacional dos Dirigentes Municipais da Educação (Undime); consultor do Fundo das Nações Unidas para a Infância (Unicef) para assuntos de educação, em 1997; consultor do Fundescola, de 1997 a 2000; membro do Conselho Consultivo do Instituto Nacional de Estudos e Pesquisas Educacionais Anísio Teixeira (Inep) do Ministério da Educação; membro da Câmara de Educação Básica do Conselho Nacional de Educação (2004-2012), tornando-se parte da comissão responsável por redigir as Diretrizes Curriculares Nacionais para a Educação Escolar Quilombola. 
certificadas. Essa conjunção de fatores colocou o estado da Bahia em destaque frente à necessidade de implementação de políticas de diversidade.

Nesse cenário, de influências internas e externas, destacam-se cinco momentos que antecederam e motivaram, direta e indiretamente, a construção da proposta de política estadual de educação para comunidades quilombolas no estado da Bahia: 1) a criação de uma coordenação para implementação da Lei ${ }^{\circ}$ 10.639/2003 na SEC/BA, em 2008; 2) demandas das comunidades quilombolas à $\mathrm{SEC} /$ BA; 3) coordenação de Diversidade da SEC e o Grupo Intersetorial para Quilombos (GIQ); 4) formação de lideranças e de professores quilombolas; e 5) o I Fórum Baiano de Educação Quilombola. A seguir discutiremos cada um desses momentos e suas inter-relações.

\section{Criação de uma coordenação para implementação da Lei $n^{\circ}$ 10.639/2003 na SEC/BA}

A coordenação para implementação da Lei ${ }^{\circ}$ 10.639/2003 na Secretaria da Educação do Estado da Bahia nasceu com o nome de Coordenação de Diversidade Negra, de Gênero, Sexualidade e Direitos Humanos. Em entrevista realizada em 2012 com membro desta Coordenação na época, foi dito que a Secretaria queria que o nome fosse Coordenação Étnico-Racial de Gênero, Sexualidade e Direitos Humanos. Para o entrevistado, a expressão "étnico-racial é mais palatável para o ego do brasileiro", ao invés de diversidade negra.

Tal iniciativa de criação da Coordenação de Diversidade ${ }^{15}$ se deu sob algumas pressões internas e externas à SEC/BA. Internamente havia um grupo de servidores negros, vinculados à discussão racial e interessados na ampliação do debate e implementação da Lei $n^{\circ} 10.639$. Estes servidores, de acordo

15 Para referir-me a essa Coordenação, optei por usar o nome "Coordenação de Diversidade", de forma a evitar possível confusão em função das alterações constantes do nome da coordenação, ora chamada de Coordenação de Diversidade Negra, de Gênero, Sexualidade e Direitos Humanos, ora Coordenação de Raça, Gênero, Sexualidade e Direitos Humanos, ora Coordenação de Educação para as Relações Étnico-raciais e Diversidade, ora Coordenação de Educação para a Diversidade, Relações Raciais e Educação Quilombola. E no cotidiano comumente denominada pela equipe da SEC/BA e de consultoria das Diretrizes como Coordenação de Diversidade. com informantes, criaram, em 2007, um grupo de trabalho para formular um documento na intenção de que se tornasse uma política voltada para a implementação da Lei. Parte desses servidores tinha envolvimento com o Fórum Estadual Permanente de Educação e Diversidade Étnico-Racial (FEDER$\mathrm{BA}$ ), criado em 2005. O FEDERBA não desenvolveu um papel ativo nos seus anos iniciais. Com a criação, em 2008, da Coordenação de Diversidade na SEC/BA, esta Coordenação teve um papel fundamental na articulação, divulgação e animação do FEDERBA. Um dos membros da Coordenação de Diversidade da SEC atuou como secretário executivo do Fórum: realizava convites públicos para as reuniões, publicava matérias informativas no Blog do FEDERBA, organizava reuniões, promovia articulação do Fórum com instituições públicas e de governo, assim como atuava como representante político do Fórum.

Outro fator interno importante para a criação de procedimentos específicos destinados à implementação da Lei ${ }^{\circ} 10.639$, que incluíram a criação de uma coordenação responsável pela temática na SEC/BA, foi o perfil do consultor do Secretário de Educação na época. Miguel Gonzáles Arroyo foi assessor da Secretaria Estadual de Educação entre 2007 e 2009, na gestão do secretário Adeum Hilário Sauer. Arroyo é professor titular emérito da Faculdade de Educação da Universidade Federal de Minas Gerais (UFMG) e foi Secretário Adjunto de Educação da Prefeitura Municipal de Belo Horizonte, coordenando e elaborando a implantação da proposta político-pedagógica Escola Plural, dedicando-se aos estudos e práticas da educação popular, educação do campo, e, nos últimos anos, publicou sobre o tema de políticas educacionais, igualdade e diferenças. Durante esse período, Arroyo esteve muito próximo da também professora da UFMG, Nilma Lino Gomes, relatora das Diretrizes Curriculares Nacionais para a Educação Escolar Quilombola, pesquisadora e atuante política no tema das relações étnico-raciais.

Miguel [Arroyo] foi importante porque ele tencionava as pessoas da SEC, da alta cúpula, perguntando 'Como é que no estado da Bahia, majoritariamente negro, vocês não tem nenhuma política de inclusão da história e cultura africana?' Então essas forças, 
esse campo de forças, é que fez com que a SEC tomasse a decisão de chamar alguém pra criar essa coordenação. (ENTREVISTADA A, 2012).

Outro dado interno, explicitado pela então coordenadora de diversidade, que serviu, a seu modo, para justificar a criação da Coordenação de Diversidade foi uma suposta ausência de profissionais capacitados na SEC/BA para debater a Lei e formular proposições. Essa suposta ausência de pessoas qualificadas para a temática e com função compatível constrangia uma parte da equipe, que passou a ser constantemente pautada por grupos sociais interessados, exigindo da SEC/BA propriedade no debate e ações de implementação da Lei $n^{0} 10.639 / 2003$.

Na verdade, foi através de uma amiga minha, [...] servidora da CAR, que é minha colega de faculdade. Nós tínhamos dentro da SEC uma amiga comum, [...] que era coordenadora de Projetos Especiais, e [...] porque aí tem uma demanda externa à SEC, das pessoas chamando a SEC para se fazer representar nos espaços de debates que tem a ver com cultura negra, educação antirracista, então, não tinha ninguém, quem ia era [...].[...] é uma branca, loira, adora a cultura negra, mas não sabe nada de cultura negra. Aí ela tava representando com vários constrangimentos por causa disso, e aí pressionou a superintendente na época, que era [...] para contratar uma coordenadora para tratar das questões e desafogá-la da função, né? (ENTREVISTADA A, 2012).

Tal justificativa contradita com a afirmação de que havia um grupo de servidores negros, vinculados à discussão racial e interessados na implementação da Lei, o qual criou um grupo de trabalho na SEC para abordar a questão. Essa contradição chama atenção para a necessidade de analisar a declaração sobre possível ausência de profissionais capacitados e sugere a existência de conflitos políticos internos ao grupo de servidores na SEC/BA. Ou seja, mesmo havendo na Secretaria Estadual servidores capacitados para gerir tal coordenação, pessoas vinculadas a grupos com poder de decisão na SEC/BA sugeriram a contratação de novo profissional.

[...] disseram que esse GT, formado por essas pessoas, que era um GT de oito pessoas, seria a equipe. Quando entrei eu vi que não tinha absolutamente nada disso. Então não tinha equipe porque as pes- soas não vieram e as pessoas não vieram porque tinha uma política lá dentro; eu entrei para substituir uma pessoa que não queriam que ficasse, então, na verdade, esse GT já tinha uma pessoa para colocar lá, então, as pessoas não vieram compor a equipe. (ENTREVISTADA A, 2012).

Externamente à SEC/BA, atuaram também como motivadores para criação da Coordenação de Diversidade e implementação da Lei n ${ }^{\circ} 10.639$, organizações sociais de caráter público, vinculadas a universidades, como o CEAFRO, o Centro de Estudos dos Povos Afro-Índio-Americanos (CEPAIA); o Fórum de Quilombos Educacionais da Bahia (FOQUIBA); o Centro de Educação e Cultura Popular (CECUP); o Ilê Aiyê; secretarias municipais e do estado, como a Sepromi, que já vinha realizando trabalhos com populações negras e quilombolas, com realização de diagnósticos econômico-sociais para elaboração de projetos de geração de renda.

De acordo com um membro da Coordenação de Diversidade, em entrevista realizada em 2012, havia duas pressões, uma interna e uma externa, no ano de 2008, para a criação de tal Coordenação. Segundo informações da entrevista, a pressão interna se deu pelo Movimento Negro, na figura do deputado federal, Luiz Alberto, ${ }^{16}$ que na época era o Secretário de Políticas de Promoção da Igualdade Racial (Sepromi). E pressões externas promovidas por consultores da SEC/BA e organizações do movimento negro que, nos eventos em que a SEC/BA estava presente, constrangia pelo fato de, até aquele momento, não ter nenhuma política no estado de implementação da Lei n ${ }^{\circ}$ 10.639/2003.

Outro dado importante é compreender que, no momento de criação da Coordenação de Diversidade, já havia outros órgãos/secretarias do governo do estado trabalhando com comunidades negras e quilombolas. Exemplo disso é a Sepromi, que

16 Luiz Alberto Silva dos Santos, natural de Maragogipe (Bahia) - município que atualmente conta com 12 comunidades quilombolas certificadas -, técnico químico de formação, filiado ao Partido dos Trabalhadores (PT) desde 1980. Foi o primeiro deputado federal negro eleito pela Bahia. Teve cinco mandatos como Deputado Federal pelo estado da Bahia (1997-2015). Foi candidato a Deputado Federal pelo PT nas eleições de 2014, porém não foi eleito. Licenciou-se do mandato de Deputado Federal na Legislatura 2007-2011 para exercer o cargo de Secretário de Promoção da Igualdade Racial da Bahia, de 6 de fevereiro de 2007 a 11 de agosto de 2008. 
desde 2007 desenvolve ações e políticas para esse público no estado.

A informação que eu tinha na UFBA, no começo, era que o Estado sempre esteve muito distante das comunidades quilombolas, uma distância gigantesca, foi assim que foi informado para mim. Contudo, essa informação não era completa. A Sepromi já havia feito um bom levantamento das comunidades quilombolas com material, apostilas escritas, vídeo produzido, CD-ROM, com bastante informação sobre as comunidades, e aí eu me dei conta que não havia comunicação entre os setores do estado. Obviamente também tinha feito mapeamento, tinha indicado ações, mas não havia diálogo entre as instituições. [...] Ações pulverizadas, bastantes separadas, então, por dedução, com pouco impacto para as comunidades quilombolas. (ENTREVISTADO B, 2012). ${ }^{17}$

\section{Demandas das comunidades quilombolas à SEC/BA}

De acordo com dados da Fundação Cultural Palmares (FCP), existem 2.958 comunidades quilombolas certificadas no Brasil, até maio de 2017, e a Bahia consta como o primeiro estado brasileiro em número de comunidades quilombolas certificadas (734). A comunidade de Pitanga dos Palmares, município de Simões Filho, e Lage dos Negros, município de Campo Formoso, foram certificadas, respectivamente, nos anos de 2004 e de 2005. Estas comunidades mantêm presença nas instâncias de representação civil para comunidades quilombolas no governo, em conselhos e fóruns (FUNDAÇÃO CULTURAL PALMARES, 2017). Além de atuarem nas instâncias de representação pública, as comunidades quilombolas de Pitanga dos Palmares e Lage dos Negros (citadas em entrevista e verificadas em consulta a documentos) se mostraram elaboradoras de demandas de educação para a SEC/BA.

Eu recebia demandas que já tinham chegado à SEC e que não tinham sido respondidas, de criação de escolas em comunidades quilombola. Tinha, por exemplo, uma demanda histórica do povo lá de Pitanga dos Palmares, inclusive com um diagnóstico bem fundamen-

17 Entrevista realizada com o Consultor para elaboração do texto base das Diretrizes Curriculares Estaduais para a Educação Escolar Quilombola do Estado da Bahia, no dia 28 de setembro de 2011, em Salvador, Bahia. tado das condições da comunidade e da necessidade de uma escola para atender a comunidade. Tinha uma demanda de Lages dos Negros para criação de uma escola também. Então começaram a chegar demandas. [...] Então, como você vai construir uma escola se você não sabe o número de estudantes, de demanda de Ensino Médio que tem em Lage dos Negros, em Pitanga de Palmares? Então, a falta de dados para informar a construção da política era um problema sério lá dentro. (ENTREVISTADA A, 2012).

Desde janeiro de 2004, o último regimento publicado pela Secretaria de Educação do Estado da Bahia contempla, na sua estrutura, as Coordenações de Educação de Jovens e Adultos; de Educação Profissional; de Educação Indígena e do Campo; de Educação Especial. Estas coordenações estão vinculadas à Diretoria de Educação e suas Modalidades, que, por sua vez, está situada na Superintendência de Desenvolvimento da Educação Básica. O que isso significa? Significa que o governo do Estado reconhece determinada especificidade de educação, inclui como modalidade específica de educação e, consequentemente, aloca recursos para o desenvolvimento de ações e políticas. No caso das coordenações indígena e do campo há recursos oriundos do governo federal, em razão da existência de uma política nacional. No caso da Coordenação de Diversidade, ela foi instituída em 2008, não está legalmente instituída na estrutura regimental da SEC/BA, o que fragiliza a captação e a operacionalização dos recursos e o desenvolvimento do trabalho. Essa Coordenação não tem dotação orçamentária do governo federal, dependendo exclusivamente do governo estadual, e não integra formalmente a estrutura da SEC/BA.

Eu entrei já com Coordenação Indígena com anos na SEC, Coordenação de Educação Especial que já tinha anos, com muito recurso na SEC, indígenas com recurso grande do MEC [...] e o Campo com um grande programa, Saberes da Terra. Na verdade, quando eu entrei, o Campo estava em crise. Dirigindo tudo isso, tinha uma figura [...] que tinha muitos problemas de compreensão de como deveria ser a relação entre movimento social e secretaria estadual de educação [...] Então é importante dizer que a única Coordenação criada pós-Wagner (governador), que não estava na estrutura da SEC, era essa, que estava sendo criada naquele momento. (ENTREVISTADA A, 2012). 
A criação de uma Coordenação de caráter estadual responsável para atuar em comunidades negras e quilombolas - comunidades historicamente sem atendimento do Estado a seus direitos básicos - e a ausência de fonte de recurso específica do Estado e da Secretaria para execução das demandas e de atividades comprometeram e limitaram a atuação da referida Coordenação, diante das demandas elaboradas pelas comunidades quilombolas.

Então, nessa reunião de planejamento eu disse: 'Tem quilombos também, tem que ter alguma política para responder às demandas de escolas de quilombos'. Aí todo mundo se assustou: 'Precisa de uma política específica para quilombos?' Então, a partir disso, isso criou alguma coisa dentro da SEC, que aí eu acabei, como é que diz, sendo conduzida para atuar aí, nesse campo aí também. (ENTREVISTADA A, 2012).

A partir dos relatos, é possível vislumbrar o modo pelo qual uma decisão governamental (projeto, políticas e compromissos partidários) pode estar fundada em tomadas de posição de determinados atores (projetos e compromissos pessoais). Uma questão é o contexto político favorável e a pressão das organizações sociais; outra é o investimento necessário para legitimar e consolidar as ações de tais Coordenações.

Essa abordagem é importante para compreender como o surgimento de um "público novo" (sujeitos da educação escolar quilombola) acaba não podendo ser efetivamente contemplado se ele não conseguir se projetar na estrutura do Estado, isto é, conquistar uma pasta específica, recursos específicos, recursos humanos etc. Ao mesmo tempo, tal projeção pode acabar tornando-se uma "camisa de força" para os grupos que exigem reconhecimento, no sentido de ter que responder às exigências e à burocracia do Estado. Este é um assunto importante e a avançar nos debates e elaborações de políticas diferenciadas para grupos étnico-culturais e de diversidade.

Esses foram os problemas gerados para pagamento das consultorias, porque tudo vinha do recurso do Campo, tá entendendo? [...] Então a gente não tinha nada, porque no MEC também não tinha nada para quilombos, tá entendendo? O MEC não tinha políticas para quilombos. (ENTREVISTADAA, 2012).

No relato acima, a entrevistada afirma a ausência de recurso específico tanto em nível de governo federal, quanto em nível de governo estadual. O que havia no momento no MEC eram projetos e programas específicos, como o Programa Brasil Quilombola, que financiava recursos para serem utilizados com formação de professor, compra de equipamentos, produção de material didático, infraestrutura e merenda escolar. Não havia ainda uma política pública que implicasse dotação orçamentária específica para atendimento das demandas. A aprovação das Resoluções CNE n ${ }^{\text {os }} 4$ e 7/2010, que tornaram a educação escolar quilombola uma modalidade de educação nacional, era recente.

\section{Coordenação de Diversidade da SEC/BA e o Grupo Intersetorial para Quilombos (GIQ)}

Neste tópico temos outro tema importante a ser abordado: o desconhecimento generalizado atribuído à equipe de Coordenação de Diversidade pelos entrevistados acerca do tema, antes de começarem a trabalhar nele. Aqui nos parece inverter o princípio a que estamos acostumados a pensar como normal, no qual primeiro há um conhecimento sobre o tema e depois a produção de uma política.

Então, eu não entrei nem para trabalhar com educação quilombola, porque eu não sabia nada de quilombos, eu nunca tinha trabalhado nada, absolutamente nada com quilombos, e eu achava que era uma demanda tão densa que não era ali que deveria ficar. [...] Aí quando eu convidei [...], convidei para duas coisas, uma pra trabalhar com juventude e também com quilombos, principalmente, que aí tem uma coisa importante que esqueci de dizer, em 2008, que foi importante para incorporar quilombos como uma ação, que foi o Grupo Intersetorial pra Quilombos da Sepromi. (ENTREVISTADA A, 2012).

O Grupo Intersetorial para Quilombos (GIQ) foi criado através do Decreto $\mathrm{n}^{\circ} 11.850$ de 23 de novembro de 2009 (BAHIA, 2009) - que institui a Política Estadual para Comunidades Remanescentes de Quilombos - e composto por representantes das seguintes Secretarias: SEAGRI, SEMA, SESAB, SEDUR, SEDIR, SEC, SECTI, SETRE, SEDES, SEC. ${ }^{18}$ Ao GIQ era atribuído o desenvolvimento e

18 Secretaria de Agricultura (SEAGRI), Secretaria do Meio Ambiente (SEMA), Secretaria da Saúde do Estado da Bahia (SESAB), Secretaria de Desenvolvimento Urbano da Bahia (SEDUR), Secretaria de Desenvolvimento e Integração Regional (SEDIR), 
execução dos Planos de Desenvolvimento Social, Econômico e Ambiental Sustentáveis para Comunidades Remanescentes de Quilombos, tendo por objetivo nortear a implementação da política. O GIQ estava institucionalizado na Sepromi. Antes da instituição do GIQ já havia trabalhos, desde 2007, de algumas secretarias e órgãos com as comunidades quilombolas no estado, tais como: Sepromi, CDA/SUAF/SEAGRI, SEDES, SEDUR, Ingá/SEMA. ${ }^{19}$

A participação de representantes da Coordenação de Diversidade da SEC/BA no GIQ provocou uma atenção destes para as comunidades quilombolas. As viagens realizadas, na época, pela coordenadora da Coordenação de Diversidade como demanda de participação no GIQ, ouvindo os quilombolas sobre a situação da educação nas comunidades, foram fator propulsor para a questão, gerando sensibilização. Até então, a coordenadora desconhecia a realidade dessas comunidades, mesmo sendo ela ativista antiga de movimentos negro em Salvador. Aqui se entrelaçam questões destacadas anteriormente: ausência de um compromisso inicial de trabalho da Coordenação de Diversidade com as populações quilombolas; ausência de conhecimento sobre o tema e a realidade do público a ser trabalhado; ausência de recurso na Coordenação de Diversidade para desenvolver as ações.

Aí o seguinte, a gente não tinha dinheiro aqui, acabou o dinheiro, aí a gente ficou só fazendo viagens pelo GT Intersetorial para Quilombos. [...] essa amiga que me levou para a SEC, e que ela coordenava o Núcleo de Ações Quilombolas da CAR, aí eu passei a participar e viajar; na verdade, isso foi a grande questão, foi quando eu tomei conhecimento da realidade quilombola, eu cheguei nas comunidades e vi o sofrimento das pessoas e vi a ausência total de tudo, e via situações, para você ter uma ideia, ali meu Deus, Getsemani, no Baixo Sul, uma senhora dizendo: 'Minha filha, eu

Secretaria de Ciência, Tecnologia e Inovação do Estado da Bahia (SECTI), Secretaria do Trabalho, Emprego, Renda e Esporte da Bahia (SETRE), Secretaria de Desenvolvimento Social e Combate à Pobreza (SEDES), Secretaria da Educação do Estado da Bahia (SEC).

19 Secretaria Estadual de Promoção da Igualdade Racial (Sepromi), Coordenação de Desenvolvimento Agrário/Superintendência da Agricultura Familiar/Secretaria de Agricultura (CDA/SUAF/ SEAGRI), Secretaria de Desenvolvimento Social e Combate à Pobreza (SEDES), Secretaria de Desenvolvimento Urbano da Bahia (SEDUR), Ingá/ Secretaria do Meio Ambiente (SEMA). não aguento mais meus filhos não terem o direito de terminar o Ensino Médio pra ser professor'. [...] Então, isso é que era a grande fascinação, era exatamente um mundo de muita pobreza, muita falta, mas, ao mesmo tempo, de muita riqueza do ponto de vista das pessoas, da qualidade humana das pessoas. Então isso é que fez com que eu voltasse dessas viagens com a certeza de que a gente tinha realmente de construir quilombos como uma ação tão prioritária quanto a implementação da Lei. E foi assim que eu comecei a trabalhar, com as duas coisas. (ENTREVISTADA A, 2012).

No relato acima é possível constatar que a entrevistada concebe a Lei ${ }^{\circ} 10.639 / 2003$ e a proposta de política para Educação Escolar Quilombola como políticas e ações diferenciadas. Embora conceba as normativas acima como propostas diferentes, são as experiências pessoais de formação que modelarão e servirão de base para se pensar a formação de novas modalidades e de sujeitos. Por exemplo, a entrevistada relata sua experiência com formação de professores no município de Salvador, referente à implantação da Lei $\mathrm{n}^{\circ} 10.639 / 2003$, e comenta a adaptação feita para os cursos de formação de lideranças e de professores quilombolas em história e cultura africana e afro-brasileira realizado pela Coordenação de Diversidade.

Eu trouxe a estruturação lá do CEAFRO, porque no CEAFRO eu tinha trabalhado com formação de professores das escolas municipais [Salvador]. E o CEAFRO montou uma estrutura que dividia em módulos: identidade, ancestralidade e resistência... Então eu trouxe esse formato e montei mais um, que era para os professores saírem com o projeto de inclusão da história e cultura africana e afrobrasileira. (ENTREVISTADA A, 2012).

É sabido que o debate sobre educação escolar quilombola emerge diante de dois grandes cenários: a) reconhecimento da identidade e do direito ao território pelas comunidades quilombolas; b) debate da educação antirracista e da educação das relações étnico-raciais. São nesses debates junto a experiências concretas e modos de fazer escola em comunidades quilombolas que vai se estruturando uma proposta pedagógica e curricular, princípios e eixos. Assim, observamos que o debate sobre educação escolar quilombola é muito recente no Brasil, bem como suas experiências escolares. 
Entretanto, em menos de uma década podemos constatar o aumento das experiências e de práticas dessa modalidade de educação, de produção de material didático e de produção de pesquisas acadêmicas. Essas iniciativas indicam especificidades dessa categoria de escola e demandam propostas e políticas diferenciadas.

A relatora do Parecer CNE/CEB n ${ }^{\circ}$ 16/2012, Nilma Lino Gomes, em entrevista, afirmou que não percebe um momento de passagem da educação das relações étnico-raciais para uma educação específica para quilombos. De acordo com o relato, desde o início do debate sobre educação quilombola, sempre se percebeu suas especificidades em relação a outras modalidades de educação e diante do debate da educação das relações étnico-raciais.

Acho que não existe um momento específico de 'passagem' de uma temática para a outra. A questão quilombola se insere dentro da discussão da educação das relações étnico-raciais e é reconhecida pelo Parecer CNE/CP n ${ }^{\circ}$ 03/2004 e Resolução CNE/CP n ${ }^{\circ}$ 01/2004. Porém, todos reconhecemos que há especificidades na implementação de uma educação que atenda aos quilombolas, o que demanda políticas e práticas educacionais que dialoguem e atendam essas realidades. (ENTREVISTADA C, 2013). ${ }^{20}$

A disputa e definição por compreensão de mundo é sempre, e ao mesmo tempo, tensa, potente e frágil. O debate da educação escolar quilombola vem crescendo, assim como seus desafios, mas nunca somente num processo linear e crescente.

Aqui temos o exemplo de construção de uma política, não apenas com iniciativa do Estado para dar conta de um público específico, mas de como essa construção da própria política é também um processo pedagógico que envolveu gestores e corpo técnico (governo), acadêmicos e organizações sociais, assim como o público, sujeito da política.

\section{Formação de lideranças e professores quilombolas}

Os cursos de formação para lideranças e professores quilombolas em história e cultura africana e afro-brasileira aconteceram, no ano de 2010, em três municípios: Valença, Bom Jesus da Lapa e Vi-

20 Entrevista realizada por e-mail com a Relatora do Parecer CEB/ $\mathrm{CNE} \mathrm{n}^{\circ} 16 / 2012$, no dia 16 de janeiro de 2013. tória da Conquista. Os cursos tinham uma estrutura modular (cada curso era composto por quatro módulos), com uma carga horária de 160 horas, tendo como eixos: identidade, ancestralidade, resistência e projeto escolar - planejamento para aplicação da Lei ${ }^{\circ} 10.639 / 2003$, que torna obrigatória a inclusão da história das culturas africanas e afro-brasileiras nos currículos escolares.

[...] e a gente começou as formações ainda em 2008, aqui em Salvador e no Território do Recôncavo, e em 2009 a ideia era continuar, pelos diversos territórios, mas aí a gente não conseguiu efetivamente. Foi a época que o secretário [...] saiu, [...] entrou outro superintendente, com outras prioridades, e também teve uma crise econômica no meio, não tinha dinheiro para nada; 2009 foi um ano difícil. (ENTREVISTADA A, 2012).

A Coordenação convidou professores da Universidade do Estado da Bahia (UNEB) com especialidade nos temas da Lei $\mathrm{n}^{\mathrm{o}} 10.639 / 2003$, africanidades e quilombos. A coordenadora de diversidade já conhecia os professores, uma vez que havia cursado o mestrado na instituição.

A partir dos relatórios elaborados por professores do curso de formação "Agora a história é outra" para lideranças e professores quilombolas, foi possível o acesso a programas dos cursos e relatos dos temas desenvolvidos. Alguns temas trabalhados no curso foram: racismo e discriminação racial no país; ensino de história e cultura afro-brasileira e africana; valores civilizatórios afro-brasileiros; quilombos; identidade quilombola; acesso à terra; educação quilombola; política estadual e nacional para quilombos. Os cursos contaram com a participação de lideranças quilombolas para falar de suas experiências, apresentação de grupos culturais locais e participação de gestores locais. Neles os professores utilizaram recursos como: imagens, vídeos curtos, filmes, leitura de textos, assim como foram distribuídos kits do MEC (material didático/ livros) para educadores quilombolas.

De acordo com o relato de um dos assessores da comissão para elaboração das diretrizes curriculares estaduais para a educação escolar quilombola, foram esses cursos que evidenciaram para a Coordenação de Diversidade as necessidades e demandas dos quilombolas, a ponto de sensibilizá-la e de transformar em pauta na SEC/BA uma série 
de ações como parte de uma política estadual para a educação escolar quilombola.

Quando a coordenadora me convida para fazer parte dessa equipe de formação que, inicialmente, era só formação das lideranças quilombolas, o que a gente foi percebendo com o processo foi que uma das demandas que surgiam dessas discussões sobre as comunidades quilombolas era exatamente o papel da escola. Uma coisa que era muito evidente era exatamente uma necessidade que as lideranças traziam, de não perceber a escola, nesse sentido a escola formal, que atuava não só na sede, mas principalmente nas comunidades quilombolas, de que essas escolas não conseguiam captar essa dimensão do que era um quilombo. As queixas eram quase que as mesmas: os professores são da sede, os professores não têm uma formação adequada para discutir a Lei $\mathrm{n}^{\circ} 10.639 / 2003$, os professores não conseguem entender o que é uma comunidade quilombola. (ENTREVISTADO D, 2011). ${ }^{21}$

É importante destacar que algumas dessas formações aconteceram integradas, mas não ao mesmo tempo, a reuniões do Fórum Permanente Estadual de Educação Quilombola e a audiências públicas para elaboração das Diretrizes Curriculares Estaduais para a Educação Escolar Quilombola. Dessa forma, os cursos de formação para professores e lideranças quilombolas, organizados pela Coordenação de Diversidade da SEC/BA foram importantes para além da troca de informações e de conhecimentos entre professores, lideranças quilombolas e pesquisadores e do espaço reflexivo para formulação de demandas. Conforme relato de um dos assessores para elaboração das diretrizes, que também atuou como professor no curso de formação "Agora a história é outra", estes cursos contribuíram para diagnosticar a situação da educação escolar desenvolvida nas comunidades quilombolas e agregar demandas relativas à educação. De acordo com a fala do assessor, os relatórios do curso e minha presença e observação durante as audiências públicas, dos seis professores que integraram a equipe do curso de formação "Agora a história é outra", apenas um participou das audiências na condição de assessor responsável pelo mapeamento das escolas existentes em comunidades quilombo-

21 Entrevista realizada com o Coordenador da Equipe de Mapeamento para elaboração do texto base das Diretrizes Quilombolas-Bahia, no dia 27 de setembro de 2011, em Salvador, Bahia. las. Junto a isso, os relatórios apresentados pelos professores dos cursos não tiveram a função de aprofundar questões e elementos diagnósticos para subsidiar o texto das Diretrizes; em geral os relatórios são sucintos e de caráter mais descritivos, sem apresentar reflexões ou análises.

\section{Fórum Baiano de Educação Quilombola}

O primeiro Fórum Baiano de Educação Quilombola, realizado nos dias 05 e 06 de novembro de 2009, aconteceu em meio a uma aproximação inicial do governo estadual (demarcada desde o início do governo, em 2007) com as articulações quilombolas locais e territoriais no estado: ações da Sepromi, SEAGRI, CAR, Grupo Intersetorial para Quilombos, instituição da política estadual para quilombos através de Decreto, assim como da articulação de organizações quilombolas na instituição de uma organização representativa em nível de estado - Conselho Estadual.

[...] e a gente conseguiu convencer [...], porque tinha um grande problema para viabilizar políticas para educação quilombola, que era ausência de dados. Então, até para você criar uma política de construção de escolas lá dentro, a gente se batia com um grande problema que, além da má vontade das pessoas de achar que não é prioridade quilombos, que quilombos têm que estar na cota geral, a gente tinha um embate de convencer que aquelas eram populações que ficaram invisíveis nas políticas públicas e que, portanto, elas mereciam um tratamento diferenciado. Então, tinha esse trabalho interno para se fazer com essas pessoas e tinha um argumento poderoso delas de que não tem dados. Aí, o que a gente fez? Vamos chamar os quilombolas, para ouvir os quilombolas! E foi assim que surgiu o Fórum, o I Fórum de Educação Quilombola. A ideia era a gente trazer o pessoal dos quilombos para cá e organizá-los em grupos para daí sair uma política, inclusive as demandas. Isso foi em novembro de 2009. Foi a primeira vez que teve comunidades quilombolas do estado inteiro vindo para encontrar com uma secretaria de estado para dizer qual é a política de educação que se quer. (ENTREVISTADA A, 2012).

Os objetivos do I Fórum, explicitados na programação do evento, ${ }^{22}$ tiveram como prioridades:

22 Ver Observatório Quilombola (2009). 
ser espaço de interlocução entre as comunidades quilombolas e a secretaria da educação na construção coletiva de uma política pública educacional para as comunidades quilombolas; identificar e sistematizar junto a lideranças e professores(as) quilombolas as demandas educacionais; subsidiar/identificar questões centrais para o processo de elaboração das Diretrizes Curriculares Estaduais para a Educação Quilombola, bem como a definição de sua concepção. O I Fórum teve como público privilegiado professores quilombolas, lideranças quilombolas e secretários municipais de educação, contabilizando, de acordo com relatório da SEC/BA, ${ }^{23}$ a participação de mais de 350 pessoas e mais de 80 comunidades quilombolas de Salvador e do interior do estado.

No convite-programação do I Fórum já constava o tema das Diretrizes Curriculares Estaduais para a Educação Quilombola como um objetivo. Diante disso, será que as diretrizes já haviam sido pensadas como uma proposta de política educacional antes de novembro de 2009? Antes da proposição nacional? Onde? Por quem? Pelas fontes consultadas e entrevistas realizadas, foi em um momento posterior ao I Fórum que o debate das Diretrizes ganhou densidade.

[...] depois que saímos do I Fórum, saímos com uma demanda apresentada por eles que a gente conseguiu responder, aí também tem a ver com os gestores. Então, mudou o superintendente, que chegou dizendo que a prioridade dele era quilombos e que, mesmo na crise, ele ia conseguir dinheiro para quilombos. Inclusive foi ele quem disse que o campo estava fazendo diretrizes estaduais para educação do campo e que ele queria que também os quilombolas construíssem diretrizes estaduais. Como isso já era uma coisa apontada, a gente saiu do I Fórum com isso na cabeça. Quando ele falou isso, deu o comando para a gente implementar. Só que as coisas dentro da SEC, primeiro que você prevê, mas não significa necessariamente que esse dinheiro vai chegar pra você. Tá entendendo? Porque na ordem de prioridade esse dinheiro pode até ter, mas a prioridade não era educação quilombola, como não é até hoje. (ENTREVISTADA A, 2012).

Meses antes da realização do I Fórum, aconteceu a mudança de Secretário da Educação e,

23 O relatório final do I Fórum foi obtido diretamente com a Coordenação de Diversidade da SEC/BA, pois o mesmo não se encontra disponível na internet. consequentemente, de Superintendentes e outros cargos de confiança. Se o Superintendente da Educação Básica anterior, Nildon Pitombo, apresentando prioridades para a política de Educação do seu Secretário, afirmava à imprensa e em reuniões que "Precisamos valorizar a matriz africana na sociedade brasileira" (DIRETRIZES..., 2010), o Secretário da Educação atual, assumindo um perfil mais administrativo de gestão, lançou os Dez Compromissos para a Educação na Bahia.

Para garantir o sucesso de todos os estudantes dos ensinos fundamental e médio no percurso educativo, proporcionando aos baianos o direito ao conhecimento de base científica, foi apresentado um plano de ações e metas pela SEC para a gestão 2011-2014. A meta é elevar os índices de aprovação para, no mínimo, 90\% nas séries iniciais, $85 \%$ nas séries finais do ensino fundamental e $80 \%$ nas séries finais do ensino médio. (BAHIA, 2011).

As metas estabelecem elevar o índice de aprovação para, no mínimo, $90 \%$ nas séries iniciais, $85 \%$ nas séries finais do ensino fundamental e $80 \%$ no ensino médio. E também assegurar que as escolas do estado e dos municípios baianos alcancem, no mínimo, as projeções estabelecidas pelo Ministério da Educação para o Índice de Desenvolvimento da Educação Básica (IDEB) no período de 2011-2014. Essas informações passaram a ter sentido diante da declaração de ex-membro da Coordenação de Diversidade, quando afirmou: "[...] a prioridade para o secretário de educação atual é avaliar o aprendizado dos alunos, o desempenho, essa coisa assim bem gerencial, do ponto de vista administrativo porque ele vem disso". (ENTREVISTADO E, 2011). ${ }^{24}$ Dos dez compromissos traçados, dois deles foram utilizados pela Coordenação de Diversidade para pleitear políticas educacionais para as comunidades quilombolas: fortalecer a inclusão educacional e inovar e diversificar os currículos escolares, promovendo o acesso dos estudantes ao conhecimento científico, às artes e à cultura.

Qual a diferença entre o secretário passado e o secretário atual? O primeiro estava pautado pelo consultor dele, que era Miguel Arroyo. Então, ele tinha uma pessoa que o orientava, que era adequada do ponto

24 Entrevista realizada com o ex-membro da Coordenação de Diversidade, no dia 26 de setembro de 2011, em Salvador, Bahia. 
de vista político, num entendimento da importância dessas coisas, porque era Arroyo. Tá entendendo? Então Arroyo tinha uma influência no governo que perdeu, inclusive de uma maneira constrangedora, no governo seguinte. Tá entendendo? Quem é hoje o consultor? Na época era um cara aí neoliberal, que todo mundo ficou horrorizado quando soube, porque, na verdade, houve uma polêmica imensa em relação aos dois consultores, a mudança, porque era mudança de perspectiva de entendimento da educação e do Brasil. Eu sei que ele tinha sido consultor de FHC. (ENTREVISTADA A, 2012).

\section{Considerações Finais}

A pesquisa utiliza a abordagem do ciclo de políticas ou policy cycle approach, formulada pelo sociólogo inglês Stephen Ball e por colaboradores (BALL, 1994; BOWE; BALL; GOLD, 1992;), a qual oferece referencial analítico para investigar programas e políticas educacionais desde a formulação inicial até a sua implementação no contexto da prática e seus efeitos. Esta abordagem enfatiza os processos micropolíticos e a ação local dos atores, apontando a necessidade de articulação dos processos macro e micro na análise das políticas públicas. Por se tratar de uma política em processo, foram analisados apenas dois dos contextos apontados por Ball (1994): o contexto de influência e o contexto da produção de texto. ${ }^{25}$

Para Mainardes (2006), referência no Brasil sobre os estudos de Ball, o contexto de influência é onde as políticas públicas são iniciadas e os discursos políticos são construídos. É nesse contexto que grupos de interesse disputam para influenciar a definição da política: finalidades, conceitos, abrangência, dentre outros. É também no contexto que os conceitos adquirem legitimidade e formam um discurso de base para a política.

No caso da política em estudo - diretrizes para educação escolar quilombola -, esta se enquadra na categoria das chamadas políticas de reconhecimento (MONTERO; ARRUTI; POMPA, 2009),

25 O presente trabalho centrou-se mais nas dinâmicas e nos processos de elaboração da política (nacional e estadual) do que na análise e no estudo dos textos produzidos. Essa opção foi feita em razão de algumas contingências: a pesquisa foi iniciada no primeiro semestre de 2011; o relatório das audiências e texto base para as diretrizes estaduais da Bahia foi concluído no segundo semestre de 2011 (setembro), sendo este um texto que não estava, até o momento, dotado de poder legal/normativo. na medida em que promovem ações que visam o respeito e a manutenção das formas de vida social pensadas como diferenciadas com relação ao padrão hegemônico. A categoria de diferenciação cultural surge como um instrumento de negociação política. Dessa forma, adaptando uma das análises elaboradas por Montero, Arruti e Pompa (2009), o contexto de influência é produzido por atores, geradores da política (de reconhecimento), que se constituem, ao mesmo tempo, como agentes políticos que elaboram demandas por direitos, tendo em vista constituírem-se como sujeitos de direitos.

Como parte da análise do trabalho desenvolvido é importante identificar e distinguir dois momentos no processo de construção das diretrizes curriculares estaduais para a educação quilombola no estado da Bahia, que se relacionam, mas não são consequentes: a criação da Coordenação de Diversidade e a elaboração de ações na SEC/BA voltadas para comunidades quilombolas.

A Coordenação de Diversidade surgiu na SEC/ BA com a proposta exclusiva de implementar a Lei $\mathrm{n}^{\mathrm{o}} 10.639 / 2003$ nas redes de ensino, e foi somente após outros determinantes de contexto que o tema quilombos passou a ser incorporado como ação também prioritária na formulação de políticas voltadas para a educação.

A Lei $n^{\circ} 10.639 / 2003$, que torna obrigatório o ensino da história e da cultura afro-brasileira e africana nas instituições de ensino, indiscutivelmente, é o grande marco legal que obriga a sua implementação pelos governos federal, estadual e municipal e, consequentemente, exige a criação de órgãos locais gestores, como as coordenações. Apesar de o texto da referida Lei não fazer referência a "quilombos" ou a "comunidades remanescentes de quilombo", ele ofereceu brechas para se pensar a educação escolar nessas comunidades. Ou seja, a discussão da educação escolar quilombola ganhou destaque a partir da regulamentação da Lei ${ }^{\circ} 10.639 / 2003$ e, posteriormente, a extrapolou, tornando-se uma modalidade de educação e sendo orientada a possuir diretrizes próprias.

A participação da Coordenação de Diversidade da SEC/BA como membro do Grupo Intersetorial para Quilombos (GIQ) e as visitas técnicas a territórios quilombolas foram fundamentais para que o corpo técnico da Coordenação de Diversidade 
tivesse conhecimento acerca das comunidades quilombolas no estado e suas demandas; a articulação conjunta de atividades e a troca de informações entre diferentes secretarias e órgãos do governo motivaram e criaram condições para que a Coordenação de Diversidade priorizasse ações voltadas às comunidades quilombolas. Não menos importante foi a articulação estadual das organizações quilombolas e de ações isoladas das comunidades que organizaram pautas exigindo ações da Coordenação de Diversidade em relação à situação das escolas em territórios quilombolas. Junto a isso, pode ser acrescentada a ação individual de atores públicos importantes, como secretários de educação e consultores técnicos na definição de prioridades, que pode auxiliar ou não o desenvolvimento de ações para grupos étnico-culturais específicos.

A ação da Coordenação de Diversidade em oferecer cursos de formação para lideranças e professores quilombolas obteve um duplo sentido: intercambiar conhecimentos e valores relacionados à Lei $n^{\circ} 10.639 / 2003$ e ao tema quilombos; e realizar um panorama - ainda que limitado - da situação das escolas quilombolas no estado, conhecimento até então precário dentro da estrutura governamental.

A realização do I Fórum Baiano de Educação Quilombola (2009) possibilitou visibilizar a existência de uma conjuntura favorável no estado ao desenvolvimento de políticas de diversidade e específica para quilombolas. Desde um cenário governamental favorável no estado e em nível nacional à implementação de políticas intersetoriais específicas para quilombos em nível estadual e nacional, forte articulação política de entidades negras e de uma organização quilombola recente em nível de estado, assim como o apoio de universidades e de seus investigadores, com existência de campos de estudos na área.

A Bahia, de forma muito particular, conseguiu articular e mobilizar os quilombolas no estado em torno da educação escolar, mas não teve êxito na aprovação do texto base para elaboração de diretrizes até 2012. ${ }^{26}$ A SEC/BA, responsável por analisar

26 O texto base referência para construção das Diretrizes da Educação Quilombola do Estado da Bahia, produzido em 2011, foi considerado na Resolução n ${ }^{\circ}$ 68, de 30 de julho de 2013 (CONSELHO ESTADUAL DE EDUCAÇÃO DA BAHIA, 2013), que estabelece normas complementares para implantação e funcionamento das Diretrizes Curriculares Nacionais para a Educação Escolar o texto base (produto das audiências) e encaminhá-lo ao Conselho Estadual de Educação parece não haver priorizado tal ação. É importante destacar que em 2011, pós-reeleição do então governador, ocorreu uma mudança na equipe de gestão da SEC/ $\mathrm{BA}$, que acabou por interferir diretamente na composição da equipe da Coordenação de Diversidade. Mesmo com alinhamento político favorável, ${ }^{27} \mathrm{a}$ nova gestão da SEC/BA não conseguiu oferecer respostas favoráveis à continuidade do trabalho interno à própria secretária, visando a uma futura aprovação das diretrizes curriculares quilombolas no estado da Bahia. De acordo com o consultor para elaboração do texto base das Diretrizes Curriculares Estaduais para a Educação Escolar Quilombola, o Conselho Estadual de Educação não foi empecilho, ao contrário "de 13 membros, 11 apoiaram de maneira entusiasta" (ENTREVISTADO D, 2011).

A sazonalidade de gestores públicos colocou em xeque a coerência entre o discurso produzido pelo governo e a efetivação de políticas. Assim como demonstrou uma defasagem entre governo e atividade política especializada, culminando num ativismo. Com isso, percebeu-se que tanto a mudança de gestores quanto a continuidade dos mesmos não serviram para consolidar políticas de educação escolar quilombola no estado. ${ }^{28}$

O cenário descrito acima é tomado na pesquisa como motivador iniciaL à demanda de construção de diretrizes curriculares para a educação escolar quilombola no estado da Bahia. Essa construção

Quilombola na Educação Básica, no Sistema Estadual de Ensino da Bahia. Resolução homologada em 18/12/2013.

27 A nova composição da SEC/BA - Amélia Maraux (Superintendente da Educação Básica), Andréia Lisboa (Coordenação de Diversidade, Relações Raciais e Educação Quilombola) e Rosângela Araújo (Diretora de Ensino e suas Modalidades) - estava alinhada politicamente ao grupo da então Ministra da Secretaria de Políticas de Promoção da Igualdade Racial (SEPPIR), Luiza Helena de Bairros, que até 2010 era Secretária Estadual de Promoção da Igualdade Racial da Bahia. Ou seja, o grupo político que estava na Secretaria de Educação cuidando da diversidade era o mesmo que estava na SEPPIR; alinhava-se politicamente governo federal e governo estadual, o que sugere uma maior potência de trabalho.

28 Enquanto isso acontecia no estado da Bahia, o texto da política nacional era concluído no primeiro semestre de 2012 e homologado em junho do mesmo ano. O CNE, apesar de ter iniciado o processo de elaboração das diretrizes posteriormente ao estado da Bahia, conseguiu publicar as diretrizes nacionais antes das diretrizes no estado. Isso se deu, em grande parte, à capacidade de articulação política do CNE no momento, assim como do enfraquecimento político da SECAD-SECADI, que acabou por acelerar o processo de aprovação das diretrizes nacionais. 
analítica temporal do processo de elaboração das diretrizes não é linear, muito menos estanque, e deve complementar-se com análise produzida a partir dos mediadores (agentes e agências) e dos espaços de mediação existentes no processo de formulação da política.

\section{REFERÊNCIAS}

ALMEIDA, Alfredo W. B. de. (Org.). Terras de preto no Maranhão: quebrando o mito do isolamento. São Luís: Projeto Vida de Negro/CCN-MA, 2002.

ARRUTI, José Maurício A. Mocambo: antropologia e história do processo de formação quilombola. São Paulo: EDUSC, 2006.

ARRUTI, José Maurício A.; MAROUN, Kalyla; CARVALHO, Ediléia. Educação quilombola em debate: a escola em Campinho da Independência (RJ) e a proposta de uma Pedagogia Quilombola. In: CUNHA, Ana Stela de Almeida (Org.). Construindo Quilombos, desconstruindo mitos: a educação formal e a realidade quilombola no Brasil. São Luís: SETAGRAF, 2011. p. 29-43.

BAHIA. Secretaria da Educação. Notícias. Pacto pela Educação investe na qualidade do ensino público na Bahia. Salvador, 2011. Disponível em: $<$ http://escolas.educacao.ba.gov.br/noticias/pacto-pela-educacao-investe-na-qualidade-do-ensino-publico-na-bahia>. Acesso em: 11 jul. 2011.

BAHIA. Decreto $\mathbf{n}^{0} \mathbf{1 1 . 8 5 0}$, de 23 de novembro de 2009. Institui a Política Estadual para Comunidades Remanescentes de Quilombos e dispõe sobre a identificação, delimitação e titulação das terras devolutas do Estado da Bahia por essas comunidades, de que tratam o art. 51 do Ato das Disposições Constitucionais Transitórias da Constituição do Estado da Bahia de 1989. Salvador, 2009. Disponível em: <http://www.sepromi.ba.gov.br/arquivos/File/decretogiq.pdf>. Acesso em: 20 maio 2017.

BALL, Stephen J. Educational reform: a critical and post-structural approach. Buckingham: Open University Press, 1994.

BOWE, Richard; BALL, Stephen; GOLD, A. Reforming education \& changing schools: case studies in policy sociology. London: Routledge, 1992.

BRASIL. Ministério da Educação. Conselho Nacional de Educação/Câmara de Educação Básica. Resolução CNE/ CEB n ${ }^{\mathbf{0}}$ 8, de 20 de novembro de 2012. Define Diretrizes Curriculares Nacionais para a Educação Escolar Quilombola na Educação Básica. Brasília, DF, 2012. Disponível em: <http://portal.mec.gov.br/index.php?option=com docman\&view=download\&alias=11963-rceb008-12-pdf\&category_slug=novembro-2012-pdf\&Itemid=30192>. Acesso em: 20 maio 2017.

BRASIL. Ministério da Educação. Diretrizes curriculares nacionais gerais da educação básica. Brasília, DF: Ministério da Educação/Secretaria de Educação Básica/Secretaria de Educação Continuada, Alfabetização, Diversidade e Inclusão/Secretaria de Educação Profissional e Tecnológica/Conselho Nacional de Educação/ Câmara Nacional de Educação, 2013. Disponível em: <http://portal.mec.gov.br/index.php?option=com docman\&view $=$ download\&alias $=13448$-diretrizes-curiculares-nacionais-2013-pdf\&Itemid=30192>. Acesso em: 20 maio 2017.

BRASIL. Presidência da República. Casa Civil. Lei no 10.639, de 09 de janeiro de 2003. Altera a Lei no 9.394, de 20 de dezembro de 1996, que estabelece as diretrizes e bases da educação nacional, para incluir no currículo oficial da Rede de Ensino a obrigatoriedade da temática "História e Cultura Afro-Brasileira", e dá outras providências. Brasília, DF, 2003a. Disponível em: <http://www.planalto.gov.br/ccivil_03/leis/2003/L10.639.htm>. Acesso em: 20 maio 2017.

BRASIL. Presidência da República. Casa Civil. Decreto no 4.887, de 20 de novembro de 2003. Regulamenta o procedimento para identificação, reconhecimento, delimitação, demarcação e titulação das terras ocupadas por remanescentes das comunidades dos quilombos de que trata o art. 68 do Ato das Disposições Constitucionais Transitórias. Brasília, DF, 2003b. Disponível em: < https:/uc.socioambiental.org/sites/uc.socioambiental.org/files/ D4887.pdf $>$. Acesso em: 20 maio 2017.

CONSELHO ESTADUAL DE EDUCAÇÃO DA BAHIA. Resolução no $\mathbf{6 8}$, de 30 de julho de 2013. Estabelece normas complementares para implantação e funcionamento das Diretrizes Curriculares Nacionais para a Educação 
Escolar Quilombola na Educação Básica, no Sistema Estadual de Ensino da Bahia. Salvador, 2013. Disponível em: $<$ http://www.sepromi.ba.gov.br/arquivos/File/decretogiq.pdf $>$. Acesso em: 20 maio 2017.

DIRETRIZES estaduais da educação quilombola para a Bahia. A Tarde Online, Salvador, 05 jul. 2010. Disponível em: <http://educacao.atarde.uol.com.br/?p=3277>. Acesso em: 07 jul. 2017.

FUNDAÇÃO CULTURAL PALMARES. Informações quilombolas. Quadro geral de comunidades remanescentes de quilombos. Brasília, DF, 2017. Disponível em: <http://www.palmares.gov.br/wp-content/uploads/2017/05/ quadro-geral-15-05-2017.pdf>. Acesso em: 20 abr. 2017.

MAINARDES, Jefferson. Abordagem do ciclo de políticas: uma contribuição para a análise de políticas educacionais. Educação \& Sociedade, Campinas, SP, v. 27, n. 94, p. 47-69, jan./abr. 2006. Disponível em: <http://www.scielo. br/scielo.php?script=sci_arttext\&pid=S0101-73302006000100003 >. Acesso em: 20 abr. 2017.

MATO GROSSO. Secretaria de Estado da Educação. Orientações curriculares: diversidades educacionais. Cuiabá, 2010 .

MELO, Willivane Ferreira de. Por uma educação escolar quilombola: a experiência do município de Santarém, Pará. Revista Observatório Quilombola, ano 2, n. 2, 2013. Disponível em: <http://www.koinonia.org.br/oq/ artigos-detalhes.asp?cod=12928>. Acesso em: 10 mar. 2017.

MONTERO, Paula; ARRUTI, José M.; POMPA, Cristina. Para uma antropologia do político. In: LAVALLE, Adrian Gurza (Org.). O horizonte da política - questões emergentes e agendas de pesquisa. São Paulo: Cosac Nayfi/UNESP, 2009. p. 145-184.

OBSERVATÓRIO QUILOMBOLA. Notícias. Estado promove o I Fórum Baiano de Educação Quilombola. Salvador, 2009. Disponível em: <http://www.koinonia.org.br/oq/noticias-detalhes.asp?cod=10221>. Acesso em: 10 maio 2017.

OLIVEIRA, Sandra N. S. de. De mangazeiros a quilombolas: terra, educação e identidade em Mangal e Barro Vermelho, Sítio do Mato-BA. 2006. 181 f. Dissertação (Mestrado em Educação) - Programa de Pós-Graduação em Educação da Universidade do Estado da Bahia (UNEB), Salvador, 2006.

PARANÁ. Secretaria de Estado da Educação (SEED). Superintendência da Educação. Educação escolar quilombola: pilões, peneiras e conhecimento escolar. Curitiba, 2010. Disponível em: $<$ http://equipemultilondrina.pbworks. com/w/file/fetch/58717533/EDUCACAO_QUILOMBOLA.pdf > . Acesso em: 20 maio 2017.

SILVA, Givânia M. da. Educação como processo de luta política: a experiência de "educação diferenciada" do território quilombola de Conceição das Crioulas. 2012. 199 f. Dissertação (Mestrado em Educação) - Faculdade de Educação da Universidade de Brasília (UnB), Brasília, DF, 2012.

SOCIEDADE MARANHENSE DE DIREITOS HUMANOS (SMDH); CENTRO DE CULTURA NEGRA DO MARANHÃO (CCN); PROJETO VIDA DE NEGRO. Vida de negro no Maranhão: uma experiência de luta, organização e resistência nos territórios quilombolas. São Luís: Sociedade Maranhense de Direitos Humanos/Centro de Cultura Negra do Maranhão, 2005. (Coleção Negro Cosme, vol. IV). 